\title{
Formulation Development and Evaluation of Gastroretentive Floating Tablets of Trazodone Hydrochloride Using Natural Polymer
}

\author{
Kavita Varma Shukla, Priya Vishwakarma*, Rekha Pathak \\ Shri Ram Institute of Pharmacy, Madhotal, Jabalpur, Madhya Pradesh, 482002, India
}

\begin{abstract}
Trazodone Hydrochloride (TRZ) is a well-known chemical compound that is used as an antidepressant that belongs to selective serotonin reuptake inhibitors (SARI). TRZ is used as anti-anxiety and sleep-inducing agent. The objective of the present investigation was formulation and evaluation of gastroretentive floating tablets of TRZ for prolongation of gastric residence time with a view to deliver the drug at the sustained and controlled manner in the gastrointestinal tract. The tablets of TRZ were prepared by direct compression method using gas generating agent and different polymer combinations such as hydroxy propyl methylcellulose and xanthan gum, guar gum. The prepared tablets of TRZ were evaluated for hardness, thickness, friability, weight variation, drug content uniformity, buoyancy lag time, total floating time, swelling index, invitro dissolution study, etc. All the compositions were resulted in adequate Pharmacopoeial limits. The varying concentration of gas generating agent and polymers was found to affect on in-vitro drug release and floating lag time. In vitro drug release of floating gastro retentive tablet of TRZ shown that the formulation F7 was found to be the best formulation as it releases $98.89 \pm 0.32 \%$ TRZ in a controlled manner for an extended period of time (up to $12 \mathrm{hrs}$ ). The release data was fitted to various mathematical models such as higuchi, korsmeyer-peppas, first order and zero order to evaluate the kinetics and mechanism of the drug release. The Optimized formulation (F7) showed no significant change in physical appearance, drug content, floating lag time, in vitro dissolution studies after $75 \% \pm 5 \%$ RH at $40 \pm 20 \mathrm{C}$ relative humidity for 6 months Prepared floating tablets of TRZ may prove to be a potential candidate for safe and effective controlled drug delivery over an extended period of time for gastro retentive drug delivery system.
\end{abstract}

Keywords: Trazodone Hydrochloride, Serotonin reuptake inhibitors, Gastro retentive, Floating tablet, Total floating time.

Article Info: Received 11 June 2019; $\quad$ Review Completed 21 July 2019; Accepted 05 Aug 2019; Available online 15 August 2019

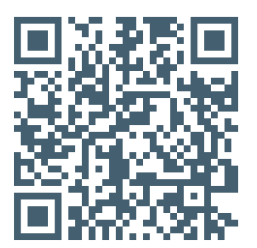

Cite this article as:

Shukla KV, Vishwakarma P, Pathak R, Formulation Development and Evaluation of Gastroretentive Floating Tablets of Trazodone Hydrochloride Using Natural Polymer, Journal of Drug Delivery and Therapeutics. 2019; 9(4-s):451-456 http://dx.doi.org/10.22270/jddt.v9i4-s.3354

Priya Vishwakarma, Shri Ram Institute of Pharmacy, Madhotal, Jabalpur, Madhya Pradesh, 482002, India

\section{INTRODUCTION}

Rapid gastrointestinal transit could result in incomplete drug release from the dosage form above the absorption zone leading to diminished efficacy of the administered dose. These considerate have led to the development of a controlled or sustained delivery system. The main purpose for developing these systems was to release the drug slowly into the gastrointestinal tract (GIT) and maintain an effective drug concentration in the systemic circulation for long time. Gastroretentive drug delivery is an approach to prolong gastric retention time, thereby targeting site- specific drug release in the upper GIT for local and systemic effect. Therefore, different approaches have been proposed to retain the dosage form in the stomach. These include bioadhesive systems, swelling and expanding systems and floating systems. Floating drug delivery or hydrodynamically balanced systems have a sufficient buoyancy to float over the gastric contents and remain buoyant in the stomach without affecting the gastric emptying rate for a prolong period [1-4]. TRZ is chemically 2-\{3-[4-(3-chlorophenyl) piperazin-1-yl] propyl $\}-2 \mathrm{H}, 3 \mathrm{H}-[1,2,4]$ triazolo[4,3-a]pyridin-3-one. It is a serotonin antagonist and reuptake inhibitor (SARI), which is a second generation antidepressant compound belonging to the class of phenyl piperazine. It acts as a serotonin agonist at high doses and low doses. The drug showing antidepressant activity is due to the blockage of serotonin reuptake by inhibiting serotonin reuptake pump at the presynaptic neuronal membrane. TRZ shows its therapeutic actions through 5 - $\mathrm{HT}_{2} \mathrm{~A}$ receptors. TRZ also induces antianxiety and sleep inducing effects [5]. It does not have similar properties to selective serotonin reuptake inhibitors (SSRIs) since its inhibitory effect on serotonin reuptake and $5-\mathrm{HT}_{2} \mathrm{C}$ receptors are relatively weak [6]. The result of $\alpha$ adrenergic action blocking and modest histamine blockade at $\mathrm{H}$ receptor due to sedative effect of TRZ. It weakly blocks presynaptic $\alpha_{2}$-adrenergic receptors and strongly inhibits postsynaptic $\alpha_{1}$ receptors. TRZ does not show any action on the reuptake of norepinephrine or dopamine within the CNS. It has fewer anticholinergic side effects than most of the tricyclic antidepressants such as dry mouth, constipation and tachycardia. TRZ metabolizes to its primary m-chlorophenyl 
piperazine (mCPP) which is a non selective serotonin receptor agonist which might outweigh the benefits of TRZ [7-10]. A majority of the investigations on natural excipients in drug delivery systems have centered on proteins and polysaccharides due to their ability to produce a wide range of materials and properties according to molecular structural alterations. In recent years, plant gums and mucilages have evoked tremendous interest due to their diverse pharmaceutical applications such as diluents, binders, disintegrants in tablets, thickeners in oral liquids, protective colloids in suspensions, gelling agents in gels and bases in suppository, thus making them attractive substitutes for costly semisynthetic and synthetic excipients. India, due to its geographical and environmental positioning, has traditionally been a good source for such products among the Asian countries [11]. With an aim to improve the absorption and oral bioavailability we took an attempt to formulate floating drug delivery systems using TRZ as the drug candidate employing methocel of various grades like K4, K15 and natural polymers like guar gum, xanthan gum.

\section{MATERIALS AND METHODS}

\section{Materials}

Trazodone $\mathrm{HCl}$ were obtained as pure sample from Sun Pharmaceutical Industries Ltd. Dewas, as gift samples along with their analytical reports. HPMC K15, K4 was obtained from Mapromax, Life sciences Pvt. Ltd. Dehradun. Xanthan gum, guar Gum, polyvinyl pyrrolidone K 30 , lactose and talc were purchased from SD Fine Chem. Limited, Mumbai. Magnesium stearate, sodium bicarbonate and citric acid were purchased from Loba Chemie Pvt. Ltd, Mumbai. All other chemical were purchased from Hi Media, Mumbai. Double distilled water was prepared freshly and used whenever required. All other chemicals used in this study including those stated were of analytical reagent (A.R.) grade.

\section{Methods}

\section{Determination of absorption maxima}

A solution of containing the concentration $10 \mu \mathrm{g} / \mathrm{ml}$ was prepared in $0.1 \mathrm{~N} \mathrm{HCl}$. UV spectrum was taken using Double beam UV/VIS spectrophotometer (Labindia-3000+). The solution was scanned in the range of $200-400 \mathrm{~nm}$.

\section{Preparation calibration curve}

$10 \mathrm{mg}$ of drug was accurately weighed and dissolved in $10 \mathrm{ml}$ $0.1 \mathrm{~N} \mathrm{HCl}$ in $10 \mathrm{ml}$ volumetric flask, to make $(1000 \mu \mathrm{g} / \mathrm{ml})$ standard stock solution (1). Then $1 \mathrm{ml}$ stock solution (1) was taken in another $10 \mathrm{ml}$ volumetric flask to make $(100 \mu \mathrm{g} / \mathrm{ml})$ sub stock solution (2), then final concentrations were prepared $5-25 \mu \mathrm{g} / \mathrm{ml}$ with $0.1 \mathrm{~N} \mathrm{HCl}$. The absorbance of standard solution was determined using UV/ VIS spectrophotometer (Labindia $3000+$ ) at $246.0 \mathrm{~nm}$. Linearity of standard curve was assessed from the square of correlation coefficient $\left(\mathrm{r}^{2}\right)$ which determined by least-square linear regression analysis.

\section{Fourier transform infrared (FTIR) spectroscopy}

The physical properties of the physical assortment were comparing with those of TRZ pure drug. Samples was assorted comprehensively through $100 \mathrm{mg}$ potassium bromide IR powder as well as compacted under vacuum at a pressure of concerning 12 psi for 3 minutes. The ensuing disc was mounted in an appropriate holder in Brukers Alpha IR spectrophotometer and the IR spectrum was recorded from $3500 \mathrm{~cm}$ to $500 \mathrm{~cm}$. The resultant spectrum was compared for any spectrum changes.

\section{Pre compression evaluation}

Flow properties and compressibility properties of powder mixture were evaluated by measurement of angle of repose, bulk density, tapped density, carr's index and hausner's ratio.

\section{Angle of repose ( $\theta)$}

The angle of repose was determined by using fixed funnel method. The physical mixtures of drug with different excipients were prepared and the accurately weighed drug powder or its physical mixture was taken in a funnel. The height of the funnel was adjusted in such a way that the tip of the funnel just touches the apex of the heap of the drug powder. The powder was allowed to flow through the funnel freely onto surface. The angle of repose was calculated using the following equation.

$$
\theta=\tan -1(\mathrm{~h} / \mathrm{r})
$$

Where, $\mathrm{h}$ and $\mathrm{r}$ are the height and radius of the powder cone respectively.

\section{Bulk density}

Both loose bulk density (LBD) and tapped density (TBD) were determined were calculated using the following formulas.

LBD $=$ Powder weight/volume of the packing

TBD = Powder weight /tapped volume of the packing

\section{Compressibility index}

The compressibility index of the granules was determined by Carr's compressibility index.

$$
\text { Carr's index }(\%)=[(\mathrm{TBD}-\mathrm{LBD}) / \mathrm{TBD}] \times 100 .
$$

\section{Hausner's ratio}

Hausner's ratio is an indirect index of ease of measuring the powder flow. It was calculated by the following formula [12$14]$.

Hausner's ratio $=$ Tapped density $/$ Bulk density .

\section{Formulation development of tablets}

\section{Direct compression method}

Different tablets formulations (F1-F8) were prepared by direct compression technique. All powders were passed through 40 meshes. Required quantities of drug and polymers were mixed thoroughly Magnesium stearate was added as lubricant. Talc was used as glidant. Lactose was used as diluents. Finally the powder mix was subjected to compression after mixing uniformly in a polybag. Prior to compression, the blends were evaluated for several tests [15]. The composition of TRZ floating tablets was shown in Table 1. 
Table 1 Formulation composition of trazodone hydrochloride gastro retentive tablets

\begin{tabular}{|l|c|c|c|c|c|c|c|c|}
\hline Excipients(mg) & F1 & F2 & F3 & F4 & F5 & F6 & F7 & F8 \\
\hline $\begin{array}{l}\text { Trazodone } \\
\text { hydrochloride }\end{array}$ & 10 & 10 & 10 & 10 & 10 & 10 & 10 & 10 \\
\hline HPMC K 15 & 90 & 120 & - & - & - & - & - & - \\
\hline HPMC K 4 & - & - & 90 & 120 & - & - & & - \\
\hline Xanthan gum & - & - & - & - & 90 & 120 & 45 & 60 \\
\hline Guar gum & - & - & - & - & - & - & 45 & 60 \\
\hline PVP K30 & 15 & 15 & 15 & 15 & 15 & 15 & 15 & 15 \\
\hline Citric acid & 5 & 5 & 5 & 5 & 5 & 5 & 5 & 5 \\
\hline NaHCO & 20 & 20 & 20 & 20 & 30 & 30 & 30 & 30 \\
\hline Mg(C $\left.\mathbf{C}_{\mathbf{1 8}} \mathbf{H}_{\mathbf{3 5}} \mathbf{O}_{2}\right)_{2}$ & 5 & 5 & 5 & 5 & 5 & 5 & 5 & 5 \\
\hline Talc & 5 & 5 & 5 & 5 & 5 & 5 & 5 & 5 \\
\hline Lactose & 110 & 80 & 110 & 80 & 110 & 70 & 100 & 70 \\
\hline Total Weight & 250 & 250 & 250 & 250 & 250 & 250 & 250 & 250 \\
\hline
\end{tabular}

\section{Evaluation of tablets}

All the tablets were evaluated for following different parameters which includes;

\section{General Appearance}

Five tablets from different batches were randomly selected and organoleptic properties such as color, odor, taste, shape were evaluated. Appearance was judged visually.

\section{Thickness and diameter}

Thickness and diameter of tablets were determined using Vernier caliper. Five tablets from each batch were used, and an average value was calculated.

\section{Hardness}

For each formulation, the hardness of five tablets was determined using the Monsanto hardness tester (Cadmach).

\section{Friability}

The friability of a sample of 10 tablets was measured using a Friability tester (Electro Lab).Ten tablets were weighed, rotated at $25 \mathrm{rpm}$ for 4 minutes. Tablets were reweighed after removal of fines (dedusted) and the percentage of weight loss was calculated.

\section{Uniformity of weight}

Twenty tablets were randomly selected from each batch individually weighed, the average weight and standard deviation of 20 tablets was calculated.

\section{Drug content}

Twenty tablets were taken and amount of drug present in each tablet was determined. The tablets were crushed in a mortar and the powder equivalent to $100 \mathrm{mg}$ of drug was transferred to $100 \mathrm{ml}$ standard flask. The powder was dissolved in $50 \mathrm{ml}$ of $0.1 \mathrm{~N} \mathrm{HCl}$ and made up to volume with of $0.1 \mathrm{~N} \mathrm{HCl}$. The sample was mixed thoroughly and filtered through a $0.45 \mu$ membrane filter. The filtered solution was diluted suitably and analyzed for drug content by UV spectrophotometer at a $\lambda \max$ of $246 \mathrm{~nm}$ using of $0.1 \mathrm{~N} \mathrm{HCl}$ as blank.

\section{In vitro buoyancy studies:}

In vitro buoyancy was determined by floating lag time as per the method described by Rosa et al [16]. The tablets were separately in a $100 \mathrm{ml}$ glass beaker containing simulated gastric fluid (SGF), pH 1.2 as per USP. The time necessary for the tablet to increase to the outside and float was determined as floating lag time. The experiments were conducted in triplicate. Total floating times were measured during in vitro dissolution studies.

\section{Dissolution rate studies}

In vitro drug release of the sample was done using USP-type II dissolution apparatus (Paddle type). The dissolution medium, $900 \mathrm{ml} 0.1 \mathrm{~N} \mathrm{HCl}$ was set into the dissolution flask maintaining the temperature of $37 \pm 0.5^{\circ} \mathrm{C}$ and rpm of 75 . One TRZ tablet was set in every container of dissolution apparatus. The mechanical assembly was permitted to keep running for 10 hours. Sample measuring $5 \mathrm{ml}$ were pulled back after each 1 hour up to 10 hours using $10 \mathrm{ml}$ pipette. The new disintegration medium $\left(37^{\circ} \mathrm{C}\right)$ was supplanted each time with a similar amount of the sample and takes the absorbance at 246nm using spectroscopy [17-19].

Mathematical treatment of in-vitro release data: The quantitative analysis of the qualities got in dissolution/release tests is simpler when mathematical formulas that express the dissolution comes about as an element of a portion of the measurement frames attributes are utilized.

Zero-order kinetics: The pharmaceutical dosage frames following this profile release a similar measure of medication by unit of time and it is the ideal method of medication release keeping in mind the end goal to accomplish a pharmacological prolonged action. The following relation can, in a simple way, express this model:

$$
\mathbf{Q}_{\mathrm{t}}=\mathbf{Q}_{\mathrm{o}}+\mathbf{K}_{\mathbf{o}} \mathbf{t}
$$

where $Q_{t}$ is the amount of drug dissolved in time $t, Q_{o}$ is the initial amount of drug in the solution (most times, $Q_{0}=0$ ) and $\mathrm{K}_{\mathrm{o}}$ is the zero order release constant.

First-order kinetics: The following relation expresses this model:

$$
\log Q_{t}=\log Q_{0}+\frac{K_{1} t}{2.303}
$$

where $Q_{t}$ is the amount of drug dissolved in time $t, Q_{o}$ is the initial amount of drug in the solution and $\mathrm{K}_{1}$ is the zero order release constant.

Along these lines a graphic of the decimal logarithm of the released measure of drug versus time will be linear. The pharmaceutical dosage shapes following this dissolution profile, for example, those containing water-solvent drugs in permeable frameworks, discharge drug in a way that is corresponding to the measure of drug staying in its inside, in 
such way, that the measure of drug released by unit of time reduce.

Higuchi model: Higuchi built up a few theoretical models to ponder the arrival of water-solvent and low dissolvable medications in semi-strong or potentially strong grids. Mathematical expressions were acquired for sedate particles scattered in a uniform grid acting as the diffusion media. The simplified Higuchi model is expressed as:

$$
\mathrm{Q}=\mathrm{K}_{\mathbf{H}^{\cdot}} \mathbf{t}^{\mathbf{1} / 2}
$$

Where $\mathrm{Q}$ is the amount of drug released in time $\mathrm{t}$ and $\mathrm{K}_{\mathrm{H}}$ is the Higuchi dissolution constant. Higuchi model describes drug release as a diffusion process based in the Fick's law, square root time dependent. This relation can be utilized to portray the drug dissolution from a few kinds of modified release pharmaceutical dosage structures, for example, transdermal systems and matrix tablets with waterdissolvable drugs.

Korsmeyer-Peppas model: Korsmeyer et al. used a simple empirical equation to describe general solute release behaviour from controlled release polymer matrices:

$$
\frac{M_{t}}{M_{\infty}}=a t^{n}
$$

where $M_{t} / M_{\infty}$ is fraction of drug released, a is kinetic constant, $\mathrm{t}$ is release time and $\mathrm{n}$ is the diffusional exponent for drug release. ' $n$ ' is the slope value of $\log M_{t} / M_{\infty}$ versus $\log$ time curve. Peppas stated that the above equation could adequately describe the release of solutes from slabs, spheres, cylinders and discs, regardless of the release mechanism. Peppas used this $\mathrm{n}$ value in order to characterize different release mechanisms, concluding for values for a slab, of $n=0.5$ for fickian diffusion and higher values of $n$, between 0.5 and 1.0, or $n=1.0$, for mass transfer following a non-fickian model. In case of a cylinder $n=0.45$ instead of 0.5 , and 0.89 instead of 1.0 . This equation can only be used in systems with a drug diffusion coefficient fairly concentration independent. To the determination of the exponent $n$ the portion of the release curve where $\mathrm{M}_{\mathrm{t}} / \mathrm{M}_{\infty}<0.6$ should only be used. To use this equation it is also necessary that release occurs in a one-dimensional way and that the system widththickness or length-thickness relation be at least 10. A modified form of this equation was developed to accommodate the lag time $(I)$ in the beginning of the drug release from the pharmaceutical dosage form:

$$
\frac{\mathrm{M}_{\mathrm{H} \cdot l}}{\mathrm{M}_{\mathbf{m}}}=\mathbf{a}(\mathrm{t}-l)^{n}
$$

When there is the possibility of a burst effect, $b$, this equation becomes:

$$
\frac{M_{4}}{M_{\mathbf{w}}}=\mathbf{a t} t^{n}+\mathbf{b}
$$

In the absence of lag time or burst effect, $l$ and $b$ value would be zero and only at ${ }^{n}$ is used. This mathematical model, also known as Power Law, has been used very frequently to describe release from several different pharmaceutical modified release dosage forms [20].

\section{Stability studies}

The optimized formulation of TRZ were packed in strips of $0.04 \mathrm{~mm}$ thick aluminum foil laminated with poly vinyl chloride by strip packing and these packed formulations were stored in ICH certified stability chambers (Thermo labs, Mumbai) maintained at $40^{\circ} \mathrm{C}$ and $75 \%$ RH for 6 months. The samples were withdrawn periodically and evaluated for their floating lag time, content uniformity and for in vitro drug release.

\section{RESULTS AND DISCUSSION}

Solubility of TRZ was freely soluble in methanol and ethanol, slightly soluble in $0.1 \mathrm{~N} \mathrm{NaOH}$, soluble in water, $0.1 \mathrm{~N} \mathrm{HCL}$ and $6.8 \mathrm{pH}$ phosphate buffers. The melting point of TRZ was 223$226^{\circ} \mathrm{C}$ and $\lambda$ max of TRZ was found to be $246.0 \mathrm{~nm}$ by using U.V. spectrophotometer (Labindia-3000+) in linearity range $5-25 \mu \mathrm{g} / \mathrm{ml}$.

Tablet powder blend was subjected to various precompression parameters Table 2 . The angle of repose values indicates that the powder blend has good flow properties. The bulk density and tapped density of all the formulations was found to be in the range of 0.489 to 0.498 (gm/ $/ \mathrm{ml})$ and 0.608 to 0.615 showing that the powder has good flow properties. The compressibility index and Hauser's ratio of all the formulations was found to be ranging between 18.586 to 20.488 and 1.228 to1.258 which show that the powder has good flow properties. TRZ tablet quality control tests such as weight variation, hardness and friability, thickness, drug content and drug release studies in different media were performed on the compression tablet. All the parameters such as weight variation, hardness, friability, thickness and drug content were found to be within limits Table 3.

Table 2 Result of pre-compression properties of TRZ FGR tablets

\begin{tabular}{|c|c|c|c|c|}
\hline F. Code & $\begin{array}{c}\text { Bulk density } \\
\text { (gm/ml) }\end{array}$ & $\begin{array}{c}\text { Tapped density } \\
\text { (gm/ml) }\end{array}$ & $\begin{array}{c}\text { Compressibility } \\
\text { index }\end{array}$ & $\begin{array}{c}\text { Hausner's } \\
\text { ratio }\end{array}$ \\
\hline \multicolumn{5}{|c|}{ Trazodone hydrochloride } \\
\hline F1 & 0.498 & 0.612 & 18.627 & 1.229 \\
\hline F2 & 0.495 & 0.608 & 18.586 & 1.228 \\
\hline F3 & 0.497 & 0.615 & 19.187 & 1.237 \\
\hline F4 & 0.495 & 0.613 & 19.250 & 1.238 \\
\hline F5 & 0.489 & 0.615 & 20.488 & 1.258 \\
\hline F6 & 0.492 & 0.612 & 19.608 & 1.244 \\
\hline F7 & 0.496 & 0.615 & 19.350 & 1.240 \\
\hline F8 & 0.498 & 0.614 & 18.893 & 1.233 \\
\hline
\end{tabular}


Table 3 Results of post compression properties of TRZ GRF tablets

\begin{tabular}{|c|c|c|c|c|c|}
\hline F. code & $\begin{array}{c}\text { Thickness* } \\
\text { (mm) }\end{array}$ & $\begin{array}{c}\text { Hardness* } \\
\text { (kg/cm2) }\end{array}$ & $\begin{array}{c}\text { Weight } \\
\text { variation* } \\
\text { (mg) }\end{array}$ & $\begin{array}{c}\text { Friability* } \\
\text { (\%) }\end{array}$ & $\begin{array}{c}\text { Drug } \\
\text { content* (\%) }\end{array}$ \\
\hline F1 & $2.85 \pm 0.12$ & $5.1 \pm 0.2$ & $255 \pm 2$ & $0.895 \pm 0.012$ & $98.98 \pm 0.12$ \\
\hline F2 & $2.86 \pm 0.25$ & $5.2 \pm 0.3$ & $249 \pm 3$ & $0.856 \pm 0.015$ & $98.45 \pm 0.25$ \\
\hline F3 & $2.84 \pm 0.32$ & $5.1 \pm 0.1$ & $256 \pm 4$ & $0.985 \pm 0.016$ & $98.65 \pm 0.23$ \\
\hline F4 & $2.86 \pm 0.14$ & $5.1 \pm 0.2$ & $257 \pm 6$ & $0.965 \pm 0.014$ & $99.02 \pm 0.41$ \\
\hline F5 & $2.89 \pm 0.25$ & $5.3 \pm 0.2$ & $259 \pm 5$ & $0.845 \pm 0.015$ & $98.65 \pm 0.21$ \\
\hline F6 & $2.83 \pm 0.23$ & $5.4 \pm 0.3$ & $252 \pm 7$ & $0.865 \pm 0.023$ & $99.06 \pm 0.45$ \\
\hline F7 & $2.81 \pm 0.32$ & $5.4 \pm 0.1$ & $249 \pm 8$ & $0.745 \pm 0.032$ & $98.85 \pm 0.52$ \\
\hline F8 & $2.83 \pm 0.45$ & $5.2 \pm 0.3$ & $248 \pm 9$ & $0.658 \pm 0.041$ & $99.12 \pm 0.41$ \\
\hline
\end{tabular}

In the present study 8 formulations with variable concentration of polymers (HPMC K4, K 15 guar gum and xanthan gum) were prepared by direct compression method and evaluated for physicochemical properties. The results of buoyancy lag time, total floating time and in vitro drug release was given in Table 4, 5 \& Fig.2. The results indicated that optimizes formulation $\mathrm{F} 7$ on immersion in $0.1 \mathrm{~N} \mathrm{HCl}$ at $37 \pm 0.5^{\circ} \mathrm{C}$ tablets immediately and remain buoyant up to $12 \mathrm{hr}$ without disintegration. These 2 factors are essential for tablets to acquire density< 1 , so that it remains buoyant on the gastric fluids. The in vitro drug release data of the optimized formulation was subjected to goodness of fit test by linear regression analysis according to zero order, first order kinetic equation, higuchi's and korsmeyer's models in order to determine the mechanism of drug release. When the regression coefficient values of were compared, it was observed that ' $r$ ' values of first order was maximum i.e. 0.974 hence indicating drug release from formulations was found to follow first order release kinetics Table 6, 7 \& Fig. 3, 4.

Table 4 Results of in-vitro buoyancy study of TRZ

\begin{tabular}{|c|c|c|}
\hline F. Code & $\begin{array}{c}\text { Floating lag times } \\
\text { (sec) }\end{array}$ & $\begin{array}{c}\text { Total floating } \\
\text { time (hrs) }\end{array}$ \\
\hline F1 & 36 & MT 12 \\
\hline F2 & 45 & MT 12 \\
\hline F3 & 40 & MT 12 \\
\hline F4 & 36 & MT 12 \\
\hline F5 & 32 & MT 12 \\
\hline F6 & 36 & MT 12 \\
\hline F7 & 35 & MT 12 \\
\hline F8 & 39 & MT 12 \\
\hline
\end{tabular}

Table 5 In-vitro drug release study of GRF tablets

\begin{tabular}{|c|c|c|c|c|c|c|c|c|}
\hline Time & \multicolumn{7}{|c|}{ \% Cumulative Drug Release* } \\
\hline (hr) & F1 & F2 & F3 & F4 & F5 & F6 & F7 & F8 \\
\hline 0.5 & $30.25 \pm 0.25$ & $29.98 \pm 0.32$ & $27.78 \pm 0.14$ & $25.65 \pm 0.23$ & $32.25 \pm 0.23$ & $33.12 \pm 0.32$ & $22.32 \pm 0.36$ & $20.12 \pm 0.25$ \\
\hline 1 & $45.56 \pm 0.32$ & $40.56 \pm 0.41$ & $39.98 \pm 0.25$ & $36.65 \pm 0.25$ & $40.23 \pm 0.32$ & $39.98 \pm 0.12$ & $36.65 \pm 0.32$ & $30.45 \pm 0.32$ \\
\hline 1.5 & $56.65 \pm 0.45$ & $53.65 \pm 0.23$ & $50.23 \pm 0.32$ & $48.89 \pm 0.32$ & $59.98 \pm 0.12$ & $60.23 \pm 0.25$ & $45.65 \pm 0.14$ & $41.32 \pm 0.41$ \\
\hline 2 & $89.98 \pm 0.65$ & $73.32 \pm 0.44$ & $69.98 \pm 0.33$ & $65.52 \pm 0.14$ & $66.45 \pm 0.41$ & $65.45 \pm 0.41$ & $55.65 \pm 0.25$ & $50.23 \pm 0.32$ \\
\hline 3 & $98.89 \pm 0.52$ & $85.56 \pm 0.33$ & $79.98 \pm 0.41$ & $73.32 \pm 0.52$ & $80.23 \pm 0.25$ & $78.85 \pm 0.23$ & $66.65 \pm 0.36$ & $56.65 \pm 0.52$ \\
\hline 4 & - & $99.12 \pm 0.25$ & $86.65 \pm 0.45$ & $82.23 \pm 0.32$ & $98.89 \pm 0.23$ & $89.98 \pm 0.32$ & $75.56 \pm 0.65$ & $63.32 \pm 0.12$ \\
\hline 6 & - & - & $98.45 \pm 0.65$ & $90.45 \pm 0.41$ & - & $96.65 \pm 0.65$ & $83.32 \pm 0.41$ & $78.89 \pm 0.12$ \\
\hline 8 & - & - & - & $98.85 \pm 0.25$ & - & - & $91.15 \pm 0.23$ & $85.56 \pm 0.23$ \\
\hline 12 & - & - & - & - & - & - & $98.89 \pm 0.32$ & $89.98 \pm 0.32$ \\
\hline
\end{tabular}

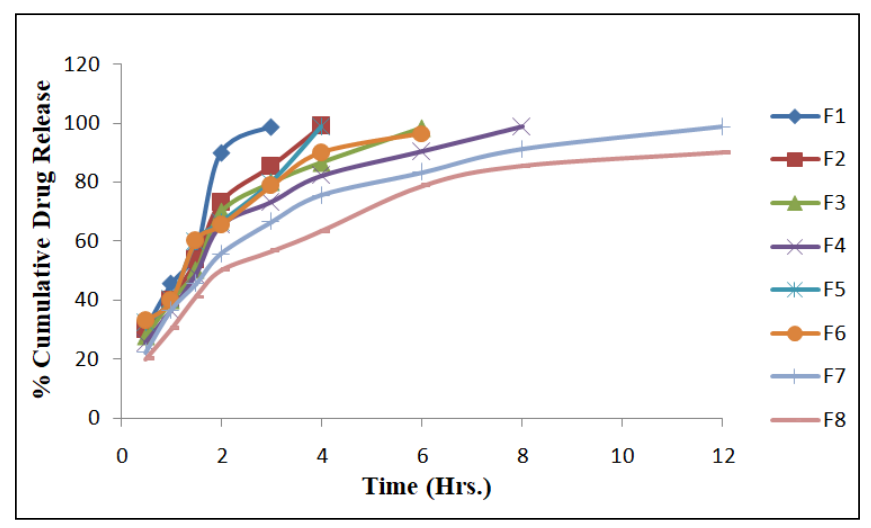

Fig.2 In-vitro drug release study of GRF tablets 
Table 6 In-vitro drug release data for optimized formulation F7

\begin{tabular}{|c|c|c|c|c|c|c|}
\hline Time (h) & $\begin{array}{l}\text { Square Root } \\
\text { of Time(h) }{ }^{1 / 2}\end{array}$ & Log Time & $\begin{array}{c}\text { Cumulative*\% Drug } \\
\text { Release }\end{array}$ & $\begin{array}{l}\text { Log Cumulative } \\
\text { \% Drug Release }\end{array}$ & $\begin{array}{c}\text { Cumulative \% } \\
\text { Drug Remaining }\end{array}$ & $\begin{array}{c}\text { Log Cumulative } \\
\text { \% Drug } \\
\text { Remaining } \\
\end{array}$ \\
\hline 0.5 & 0.707 & -0.301 & $22.32 \pm 0.36$ & 1.368 & 76.64 & 1.884 \\
\hline 1 & 1.000 & 0.000 & $36.65 \pm 0.32$ & 1.426 & 73.31 & 1.865 \\
\hline 1.5 & 1.225 & 0.176 & $45.65 \pm 0.14$ & 1.589 & 61.22 & 1.787 \\
\hline 2 & 1.414 & 0.301 & $55.65 \pm 0.25$ & 1.656 & 54.75 & 1.738 \\
\hline 3 & 1.732 & 0.477 & $66.65 \pm 0.36$ & 1.745 & 44.44 & 1.648 \\
\hline 4 & 2.000 & 0.602 & $75.56 \pm 0.65$ & 1.838 & 31.11 & 1.493 \\
\hline 6 & 2.449 & 0.778 & $83.32 \pm 0.41$ & 1.895 & 21.42 & 1.331 \\
\hline 8 & 2.828 & 0.903 & $91.15 \pm 0.23$ & 1.954 & 10.02 & 1.001 \\
\hline 12 & 3.464 & 1.079 & $98.89 \pm 0.32$ & 1.995 & 1.11 & 0.045 \\
\hline
\end{tabular}

Table 7 Regression analysis data of TRZ floating tablets

\begin{tabular}{|c|c|c|}
\hline \multirow{2}{*}{ Batch } & Zero Order & First Order \\
\cline { 2 - 3 } & $\mathbf{R}^{\mathbf{2}}$ & $\mathbf{R}^{\mathbf{2}}$ \\
\hline F7 & 0.820 & 0.974 \\
\hline
\end{tabular}

\section{CONCLUSION}

Trazodone Hydrochloride floating tablets were successfully formulated by floating technique. The optimized formulation (F7) was selected on the basis of in vitro buoyancy and in vitro drug release. The addition of gel forming agent and gas generating agent was essential to achieve in vitro buoyancy. The results of the in vitro drug release and in vitro buoyancy study showed that the optimized formulation (F7) sustained the drug release (98.89) up to $12 \mathrm{hrs}$ and remained buoyant for $>12$ hrs. Optimized formulation (F7) does not show any significant change in physical appearance, floating properties and drug release after storage at $40^{\circ} \mathrm{C} / 75 \% \mathrm{RH}$ and stable for 6 months.

\section{REFERENCES}

1. Rouge N, Leroux JH, Cole ET, Doelker E, Buri P. Prevention of the sticking tendency of buoyant minitablets filled into hard gelatine capsules. Eur J Pharm Biopharm 1997;43(2):165-71.

2. Lee JH, Park TG, Choi HK. Development of oral drug delivery system using floating microspheres. J Microencapsul 1999;16(6):715-29.

3. Robinson JR, Eriksen SP. Theoretical formulation of sustainedrelease dosage forms. J Pharm Sci 1966;55(11):1254-63.

4. Baumgartner S, Kristl J, Vrecer F, Vodopivec P, Zorko B. Optimisation of floating matrix tablets and evaluation of their gastric residence time. Int J Pharm 2000;195(1-2):125-35.

5. Haria M, Fitton A, McTavish D (1994) Trazodone. A review of its pharmacology, therapeutic use in depression and therapeutic potential in other disorders. Drugs Aging 4: 331355.

6. Marek GJ, McDougle CJ, Price LH, Seiden LS (1992) A comparison of trazodone and fluoxetine: implications for a serotonergic mechanism of antidepressant action. Psychopharmacology (Berl) 109: 2-11.

7. Fong MH, Garattini S, Caccia S (1982) 1-mChlorophenylpiperazine is an active metabolite common to the psychotropic drugs trazodone, etoperidone and mepiprazole. J Pharm Pharmacol 34: 674-675.

8. Maes M, Westenberg H, Vandoolaeghe E, Demedts P, Wauters A, et al. (1997) Effects of trazodone and fluoxetine in the treatment of major depression: therapeutic pharmacokinetic and pharmacodynamic interactions through formation of meta-chlorophenylpiperazine. J Clin Psychopharmacol 17: 358-364.

9. Kast RE (2009) Trazodone generates m-CPP: in 2008 risks from $\mathrm{m}$-CPP might outweigh benefits of trazodone. World J Biol Psychiatry 10: 682-685.

10. Kazuo Mihara, Norio Yasui-Furukori, Tsuyoshi Kondo, Masayuki Ishida, Shingo Ono, et al. (2002) Relationship Between Plasma Concentrations of Trazodone and Its Active Metabolite, m-Chlorophenylpiperazine and Its Clinical Effect in Depressed Patients. Ther Drug Monit 24: 563-6.

11. KHARWADE RS, MORE SM, MAHAJAN UN. FORMULATION AND EVALUATION OF GASTRORETENTIVE FLOATING TABLET USING HIBISCUS ROSA-SINENSIS MUCILAGE. Asian J Pharm Clin Res, Vol 10, Issue 3, 2017, 444-448

12. Patrick J. Sinko, Physical Pharmacy and Pharmaceutical Sciences, Lippincott Williams and Wilkins, 5th Edition, 2006.

13. Chein Y W. Novel drug delivery systems, Marcel Dekker, INC, 2nd edition, 1992, 140.

14. Liberman HA, Lachman L, Schwartz JB. Pharmaceutical dosage forms: Tablets, 3rd edition, Marcel Dekker, New York, 1990.

15. Ambati BR, Samyuktha Rani B, Eswar Tony D and Sivanaga Raja D. "Aceclofenac Floating Tablets- A Promising Suatained Release Dosage Form", International Journal of Drug Development and Research, 2011,3,pp 290-300.

16. Rosa M, Zia H, Rhodes T. Dosing and testing in-vitro of a bioadhesive and floating drug delivery system for oral application. Int J Pharm. 1994;105:65-70.

17. Rajesh K, Usharani E and Nagaraju R. Design and evaluation of sustained release floating tablets for the treatment of gastric ulcer, Journal of Pharmaceutical Sciences and Research, 1(4), 2009, 81-87.

18. Patil J M, Hirlekar R S and Gide P S. Trends in floating drug delivery systems, Journal ofScientific and Industrial Research, 65(01), 2006, 11-21.

19. Ritger P L, Peppas N A. A Simple Equation for Description of Solute release fickian and anomalous release from swellable devices, Journal of Controlled Release, 5(1), 1987, 37-42.

20. Brahmankar D M and Jaiswal S B. Biopharmaceutis and Pharmacokinetics: A Tretise, Vallabh Prakashan, New Delhi, $1^{\text {st }}$ edition, 2006, 335-357. 